\title{
Experiences with task-based exposure assessment in studies of farmers and tunnel workers
}

\author{
Wijnand Eduard and Berit Bakke \\ National Institute of Occupational Health, P.O. Box 8149 Dep., 0033 Oslo, Norway \\ Telephone 23195324 Telefax 23295200 E-mail wijnand.eduard@stami.no
}

\begin{abstract}
Results are described from exposure assessments in two epidemiological studies of farmers and tunnel workers. The inter and intra worker variances of exposure were used as a basis for classification of workers in groups exposed to different levels.

The between worker variability of exposure to $\alpha$-quartz showed that tunnel workers were exposed to different levels $\left(\mathrm{GSD}_{\mathrm{B}}=2.7\right)$. Classification by job type showed only $39 \%$ higher exposure of concrete workers compared to excavation workers. The influence of tasks on exposure to $\alpha$-quartz among concrete workers was studied further because the between worker variability was large $\left(\mathrm{GSD}_{\mathrm{B}}=4.3\right)$. Multiple regression of tasks on $\alpha$-quartz exposure identified two tasks that explained $51 \%$ of the total variance $\left(\mathrm{R}_{\mathrm{adj}}^{2}\right)$. Further classification of concrete workers will depend on identification of workers that use different time on these tasks.

As farmers carry out few exposed tasks per day, exposure for each task was measured separately. The between worker variability of exposure to fungal spores among farmers was high $\left(\mathrm{GSD}_{\mathrm{B}}=4.4\right)$. Classification of measurements into two broad task categories related to plant and livestock production showed that the tasks within each category were relative homogeneously exposed $\left(\mathrm{GSD}_{\mathrm{B}}=1.1\right.$ and 1.4$)$ and with geometric mean exposures that differed by a factor of 20. It therefore seems likely that farmers can be divided in groups with different cumulative exposure.

These preliminary results indicate that task-based exposure assessment may improve classification of workers by exposure.
\end{abstract}

\section{INTRODUCTION}

Exposure assessment in occupational epidemiological studies has traditionally been done by assigning workers to groups based on qualitative judgements of information as job title, company and department. The use of quantitative exposure assessment has been pioneered by Oldham and Roach (1958) in a study of coal miners in England and has been used successfully in other large scale studies. However, qualitative methods are often preferred because they are inexpensive and it is possible to include almost all the workers (Checkoway, 1989). Although such classification lack a quantitative basis it has been sufficient to demonstrate strong associations between exposure and health effects in working populations, e.g. between mining and lung fibrosis, between exposure to asbestos and progressive lung fibrosis (asbestosis), lung cancer and mesothelioma. "This is probably because observations in the past were characterised by large groups of workers being exposed for long periods of time to high levels of a small number of toxic substances, with a specific effect and with a strong correlation between occupation and exposure. Today the workforce has become more mobile which results in multiple exposures to an increasing number of chemicals at cumulative levels much lower than in the past." (Goldberg and Hémon 1993). More accurate exposure assessment is therefore a goal for future occupational epidemiological studies.

The validity of exposure classification of workers is expected to improve if classifications can be based on accurate quantitative exposure estimates. Exposureresponse relationships based on quantitative exposure data are needed to establish occupational exposure limits. Such limits are important tools for the occupational hygienist for risk assessment of occupational disease.

The use of quantitative exposure data in studies of short term effects is straight forward as it is possible to measure all relevant exposure. In studies of long term effects cumulative exposure is often considered as a biological relevant measure of exposure (Rappaport, 1991, Armstrong et al., 1992). Cumulative exposure estimates are usually based on a small number of measurements per worker which covers only a fraction of the exposed time. As exposure measurements may have high day-to-day variability non-differential mis- 
classification is likely to occur which may lead to substantial attenuation of exposure-response relationships in epidemiological studies of long term effects (Heederik et al., 1991). This bias can be reduced if the number of measurements per worker is increased but that is usually prohibited by limited resources. Therefore more efficient sampling strategies have been developed. One method is combining workers in groups with similar exposure and use all measurements within the group to estimate the exposure of each group member. Almost unbiased regression coefficients are then obtained but the estimates are less precise than regression coefficients using individual exposure data. The precision depends on the exposure contrast between groups (Tielemans et al., 1998). Identification of groups with maximal contrast is therefore of primary interest.

Exposure measurements on workers are often lognormally distributed. Exposure can then be summarised by the geometric mean (GM) and the geometric standard deviation (GSD) which are the anti-logs of the arithmetic mean and the standard deviation of the log-transformed exposure data, respectively.

Information on tasks that workers carry out can improve the accuracy of exposure estimates in two ways; inhomogeneous groups may be sub-divided in smaller groups with more similar exposure; and if the task pattern varies over time cumulative exposure may be computed with better accuracy from the duration of the tasks and their estimated exposure levels (Preller et al., 1995).

Here were report preliminary results from two epidemiological studies of farmers and tunnel workers. We wanted to try out task-based exposure assessment to estimate cumulative personal exposure, as workers carried out many different tasks with probably different exposure levels.

\section{METHODS}

Due to different work organisation in the two populations different sampling strategies were used. In farming several exposed tasks, especially those related to the harvest, are carried out only one or a few days per year and their completion is strongly dependent on the weather. Exposed work is often separated by longer periods with non-exposed work. Specified exposed tasks were therefore measured separately. In tunnel work this was not possible and measurements were done over the whole shift. As most tasks had variable duration the duration of the performed tasks was recorded at the end of the day.

\section{Study of tunnel workers}

\section{Sampling strategy}

Because workers often change work sites, it was necessary to carry out exposure measurements on several different sites. The selected sites were considered to be representative for tunnel excavation in Norway. The workers were assigned to groups based on job title. The day of the sampling was chosen at random, and the workers carried equipment for at least two work shifts. To measure all selected tasks at least 12 persons and 24 measurements were required in each main job group. In this presentation two groups of workers with different jobtitles were selected; excavation work and concrete work. At the beginning of each site visit, an overview of the work to be performed on a given day was obtained from the site superintendent. From this overview jobs available for sampling were identified.

\section{Measurements of dust exposure}

Personal samples of airborne respirable and total dust were collected. Total dust was collected on acrylic copolymer membrane filters in standard aerosol monitors. Respirable dust was collected on cellulose acetate filters using Casella cyclones. The sampling time varied from 5 to 7 hours which was considered representative for the whole work shift. Dust was analysed by gravimetry and $\alpha$-quartz was analysed in the respirable dust fraction by X-ray diffraction.

\section{Study of farmers}

\section{Sampling strategy}

Exposure of 13 specific tasks was measured with sampling time limited to $1 \mathrm{~h}$. It was planned to do 30 measurements on each task in order to estimate standard deviations with a confidence interval of $80 \%$ to $134 \%$ of the true value (Snedecor and Cochran, 1989). A total of 290 farms were randomly selected among the participants of a cross-sectional study of farmers carried out in three counties of south-eastern Norway (Melbostad et al., 1997). A smaller number of farms were actually visited as we could not reach all farms on the right time and for other reasons. If possible several tasks were measured on the same farm.

\section{Measurement of dust and fungal spores}

Aerosol samples were collected by personal sampling on polycarbonate filters with a flow rate of $11 \mathrm{~min}^{-1}$ using portable battery powered pumps. Total dust was analysed with an ultra-microbalance (detection limit 3 $\mu \mathrm{g})$. Fungal spores were counted with a scanning electron microscope (Eduard et al., 1988). The detection limit of the spore count was $3 \times 10^{4}$ to $2.5 \times 10^{6}$ spores $/ \mathrm{m}^{3}$ dependent on the magnification used for counting and the volume of sampled air.

\section{Data analysis}

All exposure data were ln-transformed before statistical analyses. The exposure of tunnel workers was measured over the whole work shift and represents $8 \mathrm{~h}$ time weighted average (8h TWA) exposure. The contribu- 
tion of different tasks on exposure of tunnel workers was estimated by linear regression. The exposures in the study of farmers were computed as exposure intensities (airborne concentration during the task).

In several samples fungal spore counts were below the detection limit. The geometric mean exposure $\left(\mathrm{GM}_{\mathrm{est}}\right)$ and the geometric standard deviation $\left(\mathrm{GSD}_{\text {est }}\right)$ were therefore estimated from the data above the detection limit according to Perkins et al. (1990) separately for each task. Values for measurements below the detection limit, $\mathrm{X}_{<\mathrm{DL}}$, were estimated by the following formula:

$$
\ln X_{<D L}=\frac{n_{\text {all }} \times \operatorname{lnGM} M_{e s t}-n_{x>D L} \operatorname{lnGM} M_{x>D L}}{n_{\text {all }}-n_{x>D L}}
$$

where $\mathrm{GM}_{\mathrm{X}>\mathrm{DL}}=$ geometric mean of samples above the detection limit and $\mathrm{n}_{\mathrm{X}>\mathrm{DL}}=$ the number of samples above the detection limit.

The partition of the variance in within and between worker geometric standard deviations, $\mathrm{GSD}_{\mathrm{W}}$ and $\mathrm{GSD}_{\mathrm{B}}$ respectively, was done by one-way random effects ANOVA including workers with repeated measurements (Boleij et al., 1995).

The contribution of specific tasks to the 8h TWA exposure of tunnel workers was estimated by multiple linear regression. The dependent variable was the $\mathrm{ln}$ transformed $8 \mathrm{~h}$ TWA exposure to $\alpha$-quartz and the independent variables were the time used on different tasks. Explanatory variables were introduced by forward selection with 'p-to-enter' of $<0.2$ and kept in the model if they had 'p-to-remove' of $<0.1$. Residuals were inspected to assess the fit of the final model (Kleinbaum et al., 1988).

Statistical analyses were carried out with Systat ${ }^{\circledR}$ 8.0 and SPSS 8.0, SPSS Inc. Chicago, IL, USA.

\section{RESULTS}

\section{Study of tunnel workers}

Measurements were carried out on 8 tunnel sites in a period of two years between 1996 and 1998. In total
113 workers participated in the exposure assessment and 93 workers carried sampling equipment at least two days.

\section{Exposure}

The results of dust and $\alpha$-quartz measurements during all types of tasks are summarised in Table 1. From 84 and 81 tunnel workers 2 or more measurements were obtained of total dust and respirable dust, respectively. Sixty workers had 2 or more measurements of $\alpha$ quartz in the respirable dust fraction. The between worker variability in the two groups of tunnel workers did not improve compared to all tunnel workers for total dust and respirable dust, and the geometric mean exposures were not very different (Table 2). For $\alpha$ quartz exposure the variability was larger. Grouping resulted in a better homogeneity for excavation workers whereas the concrete workers were less homogeneous than the whole group. The contribution of different tasks on exposure to $\alpha$-quartz during concrete work was therefore estimated by linear regression, Table 3 . On the average between 0.6 and $26 \%$ of the total time was spent on 13 tasks. Two tasks were included in the final model, $\mathrm{R}_{\text {adj }} 0.51$, which constituted $38 \%$ of the total work time.

\section{Study of farmers}

Measurements were carried out on 127 farms in 19921996 during all seasons. Measurements were not done on all selected farms because of logistic reasons $(41 \%)$, retirement $(11 \%)$ or unwillingness to participate $(4 \%)$.

Table 1. Personal exposure to total dust, respirable dust and $\alpha$-quartz during tunnel work.

\begin{tabular}{lclcll}
\hline Exposure & $\mathrm{n}^{\mathrm{a}}$ & AM & Median & GM & GSD \\
\hline total dust, $\mathrm{mg} / \mathrm{m}^{3}$ & 207 & 3.55 & 2.66 & 2.75 & 2.05 \\
respirable dust, $\mathrm{mg} / \mathrm{m}^{3}$ & 210 & 1.14 & 0.99 & 0.91 & 2.12 \\
$\alpha$-quartz, $\mathrm{mg} / \mathrm{m}^{3}$ & 168 & 0.049 & 0.030 & 0.027 & 3.48 \\
\hline
\end{tabular}

${ }^{a}$ number of measurements

Table 2. Variance components of exposure to total dust, respirable dust and $\alpha$-quartz during tunnel work. Only tunnel workers with 2 or more measurements are included.

\begin{tabular}{|c|c|c|c|c|c|c|c|c|c|c|c|c|c|c|c|c|c|c|}
\hline \multirow[b]{2}{*}{ Task } & \multicolumn{6}{|c|}{ Total dust, $\mathrm{mg} / \mathrm{m}^{3}$} & \multicolumn{6}{|c|}{ Respirable dust, $\mathrm{mg} / \mathrm{m}^{3}$} & \multicolumn{6}{|c|}{$\alpha$-quartz, $\mathrm{mg} / \mathrm{m}^{3}$} \\
\hline & $\mathrm{n}^{\mathrm{a}}$ & $\mathrm{k}^{\mathrm{b}}$ & GM & GSD & $\mathrm{GSD}_{\mathrm{W}}$ & $\mathrm{GSD}_{\mathrm{B}}$ & $\mathrm{n}^{\mathrm{a}}$ & $\mathrm{k}^{\mathrm{b}}$ & GM & GSD & $\mathrm{GSD}_{\mathrm{W}}$ & $\mathrm{GSD}_{\mathrm{B}}$ & $\mathrm{n}^{\mathrm{a}}$ & $\mathrm{k}^{\mathrm{b}}$ & GM & GSD & $\mathrm{GSD}_{\mathrm{W}}$ & $\mathrm{GSD}_{\mathrm{B}}$ \\
\hline All & 193 & 84 & 2.69 & 2.06 & 1.65 & 1.70 & 195 & 81 & 0.90 & 2.13 & 1.84 & 1.57 & 151 & 60 & 0.026 & 3.61 & 2.28 & 2.69 \\
\hline Excavation & 104 & 40 & 2.27 & 2.31 & 1.82 & 1.81 & 106 & 39 & 0.89 & 2.27 & 2.03 & 1.52 & 102 & 37 & 0.023 & 3.03 & 2.43 & 1.96 \\
\hline Concrete work & 89 & 44 & 3.32 & 1.64 & 1.37 & 1.47 & 89 & 42 & 0.93 & 1.97 & 1.54 & 1.69 & 49 & 23 & 0.032 & 4.84 & 1.90 & 4.30 \\
\hline
\end{tabular}

${ }^{a}$ number of measurements

${ }^{b}$ number of tunnel workers 


\section{Exposure}

The results of measurements of dust and fungal spores during all types of farm work are summarised in Table 4. In $28 \%$ of the samples no fungal spores were found. For these samples values were estimated as described and used further in the statistical analysis. The distribution of all dust exposure measurements agreed well with the log-normal distribution, one-sample Kolmogorov-Smirnov test on the log-transformed data, $\mathrm{p}=$ 0.5 . The distribution of the fungal spore measurements resembled a log-normal distribution although not as good, Kolmogorov-Smirnov test, $\mathrm{p}=0.08$.

From 44 farmers 2 or more measurements were obtained. These measurements were used to study the within and between worker variability by one-way ANOVA, Table 5. The variability within farmers was larger than between farmers, especially for fungal spores. Breakdown by task group showed that the between farmer variability for fungal spores decreased substantially.

Exposure intensity of different work operations is shown for total dust and fungal spores in Table 6 . There were large differences in exposure intensity between different work operations. For total dust the geometric mean varied by a factor of 15 and for fungal spores by a factor of 800 . The geometric standard deviations for most separate tasks were lower than for all measurements.

Table 3. Regression analysis of $\ln$-transformed exposure to $\alpha$-quartz by different tasks in concrete work. $\mathrm{R}^{2}{ }_{\mathrm{adj}}=0.51$.

\begin{tabular}{lcccc}
\hline & $\begin{array}{r}\text { Proportion of } \\
\text { work time, } \%\end{array}$ & B & SE & p \\
\hline Variable & & -2.61 & 0.20 & $<0.001$ \\
diverse concrete work, min & 26 & -0.0040 & 0.001 & $<0.001$ \\
demolition work, min & 12 & -0.0086 & 0.001 & $<0.001$ \\
\hline
\end{tabular}

Table 4. Personal exposure intensity to total dust and fungal spores during farm work.

\begin{tabular}{lccccc}
\hline Exposure & $\mathrm{n}^{\mathrm{a}}$ & AM & Median & GM & GSD \\
\hline total dust, $\mathrm{mg} / \mathrm{m}^{3}$ & 278 & 4.0 & 1.8 & 2.0 & 3.2 \\
fungal spores, $10^{6} / \mathrm{m}^{3}$ & 278 & 5.1 & 0.44 & 0.33 & 16 \\
\hline
\end{tabular}

a number of measurements

Table 5. Variance components of exposure to total dust and fungal spores during farm work. Only farmers with 2 or more measurements are included.

\begin{tabular}{|c|c|c|c|c|c|c|c|c|c|c|}
\hline \multirow[b]{2}{*}{ Work operation } & \multirow[b]{2}{*}{$\mathrm{n}^{\mathrm{a}}$} & \multirow[b]{2}{*}{$\mathrm{k}^{\mathrm{b}}$} & \multicolumn{4}{|c|}{ total dust, $\mathrm{mg} / \mathrm{m}^{3}$} & \multicolumn{4}{|c|}{ fungal spores, $10^{6} / \mathrm{m}^{3}$} \\
\hline & & & GM & GSD & $\mathrm{GSD}_{\mathrm{W}}$ & $\mathrm{GSD}_{\mathrm{B}}$ & GM & GSD & $\mathrm{GSD}_{\mathrm{W}}$ & $\mathrm{GSD}_{\mathrm{B}}$ \\
\hline All & $118^{\mathrm{c}}$ & $44^{c}$ & 1.7 & 3.25 & 2.88 & 1.70 & 0.23 & 15 & 9.8 & 4.37 \\
\hline Animal tending & 36 & 17 & 1.5 & 3.31 & 2.64 & 1.94 & 0.06 & 14 & 14 & 1.11 \\
\hline $\begin{array}{l}\text { Harvest and other handling } \\
\text { of plant material }\end{array}$ & 38 & 14 & 1.9 & 2.94 & 3.24 & 1.00 & 1.2 & 8.7 & 8.5 & 1.37 \\
\hline
\end{tabular}

Table 6. Exposure to total dust and fungal spores during different work operations on the farm.

\begin{tabular}{|c|c|c|c|c|c|}
\hline \multirow[b]{2}{*}{ Work operation } & \multirow[b]{2}{*}{$\mathrm{n}^{\mathrm{a}}$} & \multicolumn{2}{|c|}{$\begin{array}{l}\text { total dust } \\
\mathrm{mg} / \mathrm{m}^{3}\end{array}$} & \multicolumn{2}{|c|}{$\begin{array}{c}\text { fungal spores } \\
10^{6} / \mathrm{m}^{3}\end{array}$} \\
\hline & & GM & GSD & GM & GSD \\
\hline threshing & 29 & 0.86 & 2.6 & 0.86 & 9.5 \\
\hline other grain handling & 23 & 5.1 & 3.0 & 2.0 & 8.2 \\
\hline straw handling & 8 & 2.2 & 1.7 & 1.3 & 4.4 \\
\hline hay handling & 28 & 2.5 & 3.0 & 1.9 & 6.6 \\
\hline silage handling & 16 & 0.44 & 1.8 & 0.02 & 7.8 \\
\hline sorting potatoes & 20 & 2.3 & 1.9 & 0.49 & 2.9 \\
\hline sorting onions & 16 & 6.8 & 1.7 & 16 & 2.9 \\
\hline \multicolumn{6}{|l|}{ tending of } \\
\hline dairy cows and cattle & 36 & 1.2 & 2.6 & 0.04 & 28 \\
\hline sheep and goats & 29 & 1.4 & 2.4 & 0.15 & 22 \\
\hline poultry & 32 & 5.0 & 2.9 & 0.30 & 7.4 \\
\hline swine & 32 & 3.1 & 2.3 & 0.20 & 9.7 \\
\hline handling of liquid manure & 16 & 0.71 & 1.9 & 0.09 & 2.0 \\
\hline handling of dry manure & 7 & 1.9 & 3.7 & 0.23 & 5.2 \\
\hline
\end{tabular}

${ }^{a}$ number of measurements 


\section{DISCUSSION}

The grouping of tunnel workers by the job titles excavation and concrete workers was not very successful. Relatively small differences between the geometric mean exposures of the two groups were found and the homogeneity of exposure within these groups did not improve as the $\mathrm{GSD}_{\mathrm{B}}$ values did not change substantially. Only for excavation workers the homogeneity of exposure to $\alpha$-quartz showed some improvement whereas $\alpha$-quartz exposure of concrete workers was more heterogeneous than of all tunnel workers.

Information on exposure levels of different tasks was obtained by recording the duration of the tasks performed by the concrete workers at the end of the shift as it was not possible to measure tasks separately. Multiple linear regression of time used on different tasks on $\alpha$-quartz exposure of concrete workers showed that two tasks were significant determinants of (low) exposure and explained a substantial part of the variance. These tasks were performed by only a few workers during field work while other concrete workers did not participate in this work. It seems therefore likely that further analysis of time used on different tasks may improve the estimates of cumulative exposure. The concrete workers can probably be divided further into more homogeneous subgroups with different exposure levels. Another option is to compute individual cumulative exposure from diaries on time used on different tasks for the period of interest.

Among farmers it was most rational to measure exposure of specific tasks as farmers carry out only a few exposed tasks per day, often only one. The within farmer variability may therefore be regarded as a proxy of the day-to-day variability. The within farmer variability of exposure to fungal spores was very high which indicates that measurements done on the same farmers have little dependency. This was expected as the work environment in farm buildings and outdoors were often specific to the tasks as well as materials that were handled. A substantial between farmer variability of fungal spore exposure was also found. Further study of subgroups of farmers was therefore warranted. Grouping of the measurements into two broad task categories reflecting plant and livestock production was very effective. This can be seen from the between farmer GSDs which were close to 1 and the geometric mean exposures which differed by a factor of 20 . The geometric mean exposure levels of the specific tasks showed that except silage handling, all other plant production tasks had higher exposure than livestock production related tasks. The very high within farmer variability in the two task categories with $\mathrm{GSD}_{\mathrm{W}} \mathrm{S}$ of 8.5 and 14 probably originates from the proliferation of fungi with exponential rates under favourable conditions which farmers strive to avoid. The geometric mean exposure to total dust also showed differences between tasks but grouping by production type was not very effective.

Although farmers carry out a small number of exposed tasks each day their cumulative exposure includes a greater number as several tasks depend on the season. Measuring exposure of all tasks done by each farmer to estimate cumulative exposure is too costly and time consuming to be practicable in larger studies. Furthermore, exposure levels may vary from year to year because of the weather and microbial attacks on crops in the field and during storage. Year to year variability is included in the study as measurements have been carried out over a period of 5 years.

Although fungal spore exposure showed large differences between tasks related to plant production and livestock production the cumulative exposure may not show so large differences, as farmers with livestock production also grow crops. Estimation of cumulative exposure is interesting, however, as we have previously found that livestock production was a determinant of chronic bronchitis as well as asthma in this population (Melbostad et al., 1997 and 1998).

These preliminary results show that tasks can be important determinants of exposure. Among tunnel workers more efficient groupings based on task analysis seem likely and will be subject for further study. In the farmer study exposure measurements of specific tasks was regarded as the only feasible strategy. Large differences between fungal spore exposure to different tasks were observed. The cumulative exposure of a farmer includes all exposed tasks and will be computed for farmers with different production from time used on different tasks. Other factors that influence exposure such as materials, equipment, environmental conditions, and work practice may be used to estimate exposure with better accuracy. It has been shown previously that modelled exposure to endotoxins showed a stronger relationships with lung function among pig farmers than the actual measurements (Preller et al., 1995). Estimation of exposure on a task basis is also interesting for the occupational hygienist as such data are valuable for exposure prevention purposes.

\section{ACKNOWLEDGEMENTS}

We thank the tunnel workers and farmers for participating in the study and the staff at the National Institute of Occupational Health for assistance in field and analytical work. The projects received financial support from the Working Environment Fund of the Confederation of Norwegian Business and Industry, the Agricultural Research Board of Norway, the Agricultural Investment fund, Norske Meierier (Norwegian Dairies), Gjensidige (Insurance) and Forenede (Insurance). 


\section{REFERENCES}

Armstrong BK, White E, Saracci R. Principles of exposure measurement in epidemiology. Monographs in epidemiology and biostatistics Vol. 21. Oxford: Oxford University Press, 1992.

Boleij JSM, Buringh E, Heederik D, Kromhout M. Occupational hygiene of chemical and biological agents. Amsterdam: Elsevier, 1995: 106-109.

Checkoway H, Pearce N, Crawford-Brown DJ. Research methods in occupational epidemiology. Oxford: Oxford University Press, 1989.

Eduard W, Sandven P, Johansen BV, Bruun R. Identification and quantification of mould spores by scanning electron microscopy (SEM): Analysis of filter samples collected in Norwegian sawmills. Ann Occup Hyg 1988; 32 (Suppl. 1): 447-455.

Goldberg M, Hémon D. Occupational epidemiology and assessment of exposure. Int J Epidemiol 1993; 22 (Suppl. 2): S5-S9.

Heederik D, Boleij JSM, Kromhout M, Smid T. Use and analysis of exposure monitoring data in occupational epidemiology: an example of an epidemiological study in the Dutch animal food industry. Appl Occup Environ Hyg 1991; 6: 458-464.

Houba R, Kromhout H, Heederik D. Grouping strategies for exposure to inhalable dust, wheat allergens and $\alpha$ amylase in bakeries. Ann Occup Hyg 1997; 41: 287-296.

Kleinbaum DG, Kupper LL, Muller KE. Applied regression analysis and other multivariable methods. $2^{\text {nd }}$ ed. Boston, USA: PWS-KENT Publishing Company, 1988.

Kromhout M, Symanski E, Rappaport SM. A comprehensive evaluation of within- and between-worker components of occupational exposure to chemical agents. Ann Occup Hyg 1993; 37: 253-270.

Melbostad E, Eduard W, Magnus P. Chronic bronchitis in farmers. Scand J Work Environ Health 1997; 23: 271280. Reprinted in Norsk Epidemiologi 1997; 7 (2): 273-282.

Melbostad E, Eduard W, Magnus P. Determinants of asthma in a farming population. Scand J Work Environ Health 1998; 24: 262-269.

Oldham PD, Roach SA. A sampling procedure for measuring industrial dust exposure. Br J Ind Med 1952; 9: 112119.

Perkins JL, Cutter GN, Cleveland MS. Estimating the mean, variance, and confidence limits from censored (<limit of detection), lognormally-distributed exposure data. Am Ind Hyg Assoc J 1990; 51: 416-419.

Preller L, Kromhout H, Heederik D, Tielen MJM. Modelling long-term average exposure - an application to exposure-response analysis. Scand J Work Environ Health 1995; 21: 504-512.

Rappaport SM. Selection of the measures of exposure for epidemiology studies. Appl Occup Environ Hyg 1991; 6: $448-457$.

Snedecor GW, Cochran WG. Statistical methods. $8^{\text {th }}$ ed. Ames, Iowa: Iowa University Press, 1989.

Tielemans E, Kupper LL, Kromhout H, Heederik D, Houba R. Individual-based and group-based exposure assessment: Some equations to evaluate different strategies. Ann Occup Hyg 1998; 42: 115-119. 